\title{
Supporting Transition for Mathematics and Science Students under an Assumed Knowledge Approach
}

Peter Johnston, Wendy Loughlin, Christopher Brown, Michael Williams, Dianne Watters

Griffith University, Brisbane, QLD, Australia

p.johnston@griffith.edu.au

\section{Abstract}

In Australia there is concern over the poor mathematical skills of students entering University STEM degrees (King \& Cattlin, 2015). Challenged by the introduction of an assumed knowledge approach for mathematics dependent university degrees, we noted diagnostic testing approaches (Ní Fhloinn et al., 2014) and sought to adapt the successful GetSet2 quiz that previously had been applied only to pre-requisite mathematics university entry (Burton et al., 2013). We introduced the on-line self-assessment Get Ready Maths/Science quizzes for commencing science and mathematics students. This allowed students to receive timely personalised feedback on their level of knowledge and skills compared with the expected assumed/pre-requisite knowledge for university entry. This paper reviews the design, development and initial implementation of transition quizzes under the challenges of an assumed knowledge framework, instead of a pre-requisite framework.

\section{Introduction}

Griffith University is a public funded metropolitan Australian university that has more than 45,000 students spread across five campuses. The University defines itself by inclusivity and has mature-age students, as well as students from low socio-economic and first-in-family backgrounds. In 2017 the University moved from use of subject pre-requisites for admission to an assumed knowledge framework for admission. Under this framework commencing first year students are assumed to have achieved a minimum level of knowledge in certain subjects through their senior secondary school studies, or equivalent. Assumed knowledge is not assessable, however, degrees such as Science and related degrees recommend foundational knowledge in one or more of the following Queensland Year 12 subjects: Maths (A, B or C); Physics, Chemistry or Biology.

As in many countries, in Australia there is concern over the decline in the number of high school students studying mathematics and science (Wilson \& Mack, 2014; Faulkner et al., 2016). In addition, the mathematical skills of students entering University STEM degree programs are declining, leading to low retention rates in these programs (Treacy \& Faulkner, 2015). Contributing factors are instances of removal of pre-requisites, including mathematics, for quantitative degrees and the greater diversity of the student cohort with more mature age students and those entering university through non-traditional pathways.

To assist students (and lecturers) to identify their areas of weakness, diagnostic tests have been administered at the beginning of first year in many universities. Diagnostic tests were shown to be the best predictors of future performance in an engineering course (Lee et al., 2008). Britton et al., (2007) found that such 
tests are also a good predictor of success in first year mathematics courses, however it was suggested that they need to be compulsory, as some students who did badly in the mathematics course did not do the diagnostic test as it was optional.

Due to the importance of mathematics to the study of engineering and despite pre-requisites for mathematics in place, many engineering faculties have introduced diagnostic testing to identify areas of weakness and direct students to appropriate resources/courses (Carr et al., 2015; Rylands \& Shearman, 2018; Ni Fhloinn et al., 2014). In Australia, the GetSet2 (Get Set for success Quiz) environment has been used in the engineering faculties of five partner universities (University of Southern Queensland, University of Technology Sydney, University of Queensland, University of Newcastle and University of New England) and was developed via an Australian Government Office of Learning and Teaching Grant (Burton et al., 2013). The quiz was given to engineering and applied science students, including a regional university (Wilkes \& Burton, 2015) and there was a significant correlation between quiz results and academic success in first year courses. The outcome of the study was that students undertaking the GetSet2 Quiz ( $25 \%$ of the cohort), who used feedback from the quiz, were better prepared for their first year at University and had improved grades in first year.

\section{Methodology}

The present study aimed to adapt the GetSet2 quiz environment (named herein Get Ready Maths/Science Quiz) for science students gaining entry to University Science based degrees requiring assumed knowledge in Queensland Year 12 STEM subjects. This study follows the phases of (i) design and (ii) pilot trial of a non-assessable diagnostic test adapted to an assumed knowledge framework for Maths A, Maths B, Chemistry and Biology. The pilot trial was carried out with 31 first year science students completing a second semester chemistry course in 2016 and incorporated into the learning management system, familiar to the students.

In the design phase, the Get Ready Maths/Science Quiz questions were focused on topics that required use of mathematical concepts and skills. The questions were sourced from appropriate questions from the GetSet2 question bank along with questions requiring mathematical skills from well-established mathematics and chemistry bridging courses that had a successful record of transitioning non-chemistry or mathematics students to the start of the first-year curriculum. In addition, the Get Ready Maths/Science Quiz questions were benchmarked against the Year 12 subjects defined by the Queensland Curriculum and Assessment Authority syllabus for Functional Mathematics (2006) Mathematics A (2008), Mathematics B (2008), Biology (2004) and Chemistry (2007). The diagnostic tests contained multiple choice questions; question topics and the number of questions in each topic are indicated in the table on the next page. Modularisation and sequencing of levels of questions (e.g. numeracy before algebra) to ease students into the quiz was implemented along with introductory statements prior to commencing the quiz, such as Even 
if it has been a long time since you have done high school we suggest you to have a go. Each question has an option of "Never seen before" and an option of "Can't remember how to do it". These alternate question options were included to decrease the potential for negative student reactions to content questions.

\begin{tabular}{|l|l|c|}
\hline $\begin{array}{c}\text { Year 12 subject } \\
\text { (Get Ready } \\
\text { module) }\end{array}$ & \multicolumn{1}{|c|}{ Topics } & $\begin{array}{c}\text { No. of } \\
\text { module } \\
\text { questions }\end{array}$ \\
\hline $\begin{array}{l}\text { Functional } \\
\text { Mathematics } \\
\text { (Numeracy) }\end{array}$ & $\begin{array}{l}\text { Percentage; speed \& distance; numerical } \\
\text { problem solving; decimals; percentage problem } \\
\text { solving. }\end{array}$ & 5 \\
\hline Mathematics A & $\begin{array}{l}\text { Unit conversion; scientific notation; volume; } \\
\text { proportional reasoning; mean \& median } \\
\text { scatterplots; standard deviation; simple algebra; } \\
\text { negative exponents; average value. }\end{array}$ & 10 \\
\hline Mathematics B & $\begin{array}{l}\text { Equation solving; graphs of linear functions; } \\
\text { adding two algebraic functions; simplifying an } \\
\text { expression with powers; exponential function; } \\
\text { adding different base logarithms; evaluating }\end{array}$ & 10 \\
\hline logarithms; rearranging algebraic formulae; \\
derivatives.
\end{tabular}

In the pilot trial phase, the questions were administered through the learning management system for the semester two Chemistry Course and students were asked to voluntarily complete the Get Ready Maths/Science Quiz and provide feedback on a survey. Students completed the quiz at their own pace. The voluntary quiz did not contribute to any graded assessment for the students in their course and all information arising from the quiz was de-identified. Survey questions explored aspects such as students' previous experience with the subject, their perception of their knowledge, difficulty of questions in the quiz, confidence with questions in the quiz and anxiety. Links to educational websites for understanding how to solve the question were embedded in the quiz. A 5point Likert scale was used for each response: very low, below average, average, above average and very high.

\section{Pilot Student Group Demographic}

Students were in the age range $17-29$, with $76 \%$ of students 17 to19 years-ofage at the start of their first-year studies. The 2016 students in the pilot study consisted of 14 males and 17 females. This 45:55 split was representative of 
the actual 2016 semester two Chemistry Course population which consisted of 122 males and 165 females (43:57). Students in the 2016 sample group had Overall Positions (OP) ranging from 1 to 16 , where an OP of 1 or 16 represented the top $1 \%$ or $85 \%$, respectively, of the graduating Year 12 cohort in Queensland for that year.

\section{Results and Discussion}

In preparation for introduction of an assumed knowledge framework for the university in 2017, the pilot trial of the Get Ready Maths/Science Quiz was made available to all semester two Chemistry Course students on-line through the Learning Management System (LMS). The sample students $(n=31)$ completed between one to all five of the quiz modules and took between 1 minute and 65 minutes (on their first attempt) to complete each quiz module, with the average times for each module shown in the table below. One additional student took 204 hours to complete the Chemistry module. This was attributed to not logging out of the LMS and thus not included in the analysis.

\begin{tabular}{|l|c|c|c|c|c|}
\hline $\begin{array}{l}\text { Quiz } \\
\text { Module }\end{array}$ & $\begin{array}{c}\text { No. completing } \\
\text { module } \\
\mathrm{n}(\%)\end{array}$ & $\begin{array}{c}\text { Completion } \\
\text { time } \\
(\text { mins })\end{array}$ & $\begin{array}{c}\text { Average } \\
\text { time } \\
\text { (mins) }\end{array}$ & $\begin{array}{c}\text { Mark } \\
(\%)\end{array}$ & $\begin{array}{c}\text { Average } \\
\text { Mark } \\
(\%)\end{array}$ \\
\hline Numeracy & $26(84)$ & $2-12$ & 6.39 & $20-100$ & 80.1 \\
\hline Maths A & $16(52)$ & $3-23$ & 12.9 & $10-90$ & 58 \\
\hline Maths B & $11(35)$ & $1-41$ & 13.2 & $10-100$ & 56.4 \\
\hline Biology & $11(35)$ & $2-42$ & 14.5 & $20-80$ & 58 \\
\hline Chemistry & $20(65)$ & $1-60$ & 12.6 & $10-100$ & 56 \\
\hline
\end{tabular}

Completion of the modules by the sample students revealed a preference towards completion of simpler modules, such as Numeracy and Maths A, with fewer students $(n=10,32 \%)$ completing all three mathematics modules or both science modules $(n=8,26 \%)$.

\begin{tabular}{|c|l|c|c|}
\hline $\begin{array}{c}\text { No. of } \\
\text { modules } \\
\text { completed }\end{array}$ & \multicolumn{1}{|c|}{ Quiz Module(s) } & $\begin{array}{c}\text { No. of } \\
\text { students } \\
\text { completing } \\
\text { module }\end{array}$ & $\begin{array}{c}\% \text { of } \\
\text { cohort }\end{array}$ \\
\hline 1 & Numeracy & 4 & 13 \\
\hline 1 & Chemistry & 4 & 13 \\
\hline 1 & Biology & 1 & 3 \\
\hline 2 & Numeracy, Biology & 1 & 3 \\
\hline 2 & Numeracy, Chemistry & 5 & 16 \\
\hline 2 & Numeracy, Maths A & 4 & 13 \\
\hline 2 & Numeracy, Maths B & 1 & 3 \\
\hline 3 & Numeracy, Maths A, Maths B & 1 & 3 \\
\hline 4 & Numeracy, Maths A, Maths B, Chemistry & 2 & 6 \\
\hline 4 & Numeracy, Maths A, Biology, Chemistry & 1 & 3 \\
\hline 5 & all modules & 7 & 23 \\
\hline
\end{tabular}

Surprisingly only $61 \%(n=19)$ of the sample students completed the Chemistry module, despite being enrolled in a Chemistry course at the time of completion 
of the Get Ready Quiz. A few students attempting modules that they had not studied at high school: e.g. 2 students attempted the Maths B module without prior study, but still obtained a passing mark for the module (50\% and $70 \%)$. In addition, one student attempted all modules (between 2-8 times) until they achieved $100 \%$ on each module.

Questions for each module regarding perception of student knowledge, difficulty of questions in the quiz, confidence with questions in the quiz and anxiety were captured in the follow-up survey administered after completion of the quiz, when students had almost completed their second semester of study in first year. The survey results (from $35 \%$ of the pilot cohort) for the Numeracy module illustrate the student responses for all modules including Maths A and B. Students perception of knowledge and previous experience of the questions in the module was average to very high, along with confidence with the quiz questions $(90 \%)$, and average to below average anxiety (90\%). Despite these trends, a proportion of the sample students $(20 \%)$ indicated that the level of difficulty of the Numeracy questions in the quiz were above average to very high.

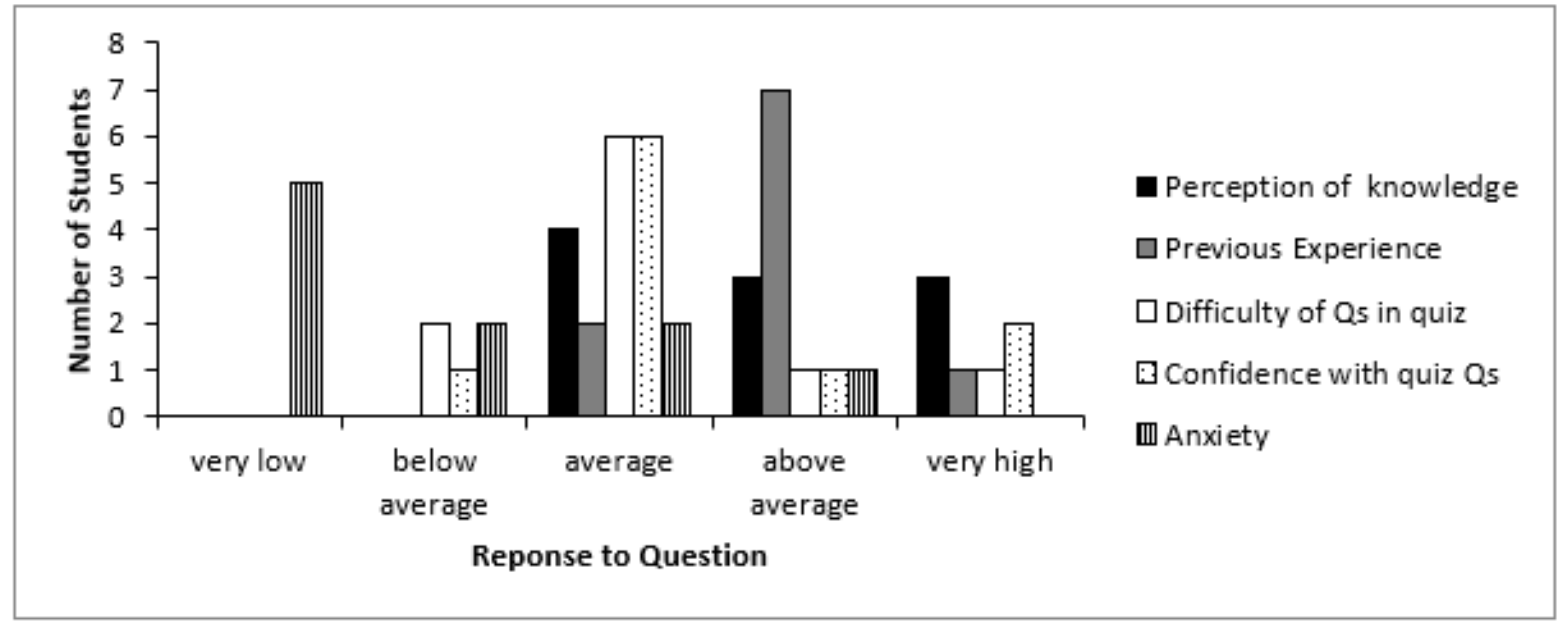

Figure 1: Survey results for Numeracy module

As anticipated, student feedback included requests for worked solutions, more detailed information as to why one answer was correct, along with internet speed complaints. Students made individual comments on the questionnaire such as 'helped me to identify where I needed to improve', 'found the quiz was both a good self-assessment tool and a good revision tool' and contrasting opinions suggested questions should be simpler or harder.

\section{Conclusion}

This study designed an effective pilot diagnostic quiz, comprised of five discipline focussed modules, for implementation under an assumed knowledge framework for Maths (A and B), Chemistry and Biology. Students completed the pilot Get Ready Quiz with appropriate completion times and grade distribution. Student engagement with completion of every module of the quiz was variable, reflecting the diversity of the student group along with the voluntary approach used in the pilot study. In going forward, it is clear personalised feedback and/or worked answers need to be included for students in any future versions. The low uptake with Get Ready Quiz should be considered in the context of literature 
reports (see reference list) on the positive impact of other diagnostic tests for first year University students, as well as student feedback. This contributes to the viewpoint that diagnostic testing, such as the Get Ready Quiz, should be compulsory, to best support University mathematics and science students, that commence study under an assumed knowledge framework.

\section{References}

Burton, L., Dowling, D., \& Albion, M. (2013) Get Set for Success: Office for Learning and Teaching Final Report. ISBN PDF 978-1-74361-484-6.

Britton, S., Daners, D. \& Stewart, M. (2007). A self-assessment test for incoming students. International Journal of Mathematical Education in Science and Technology, 38, 861-868.

Carr, M., Fidalgo, C., Bigotte de Almeida, M.E., Branco, J.R., Santos, V., Murphy, E. \& Ní Fhloinn, E. (2015). Mathematics diagnostic testing in engineering: an international comparison between Ireland and Portugal. European Journal of Engineering Education, 40, 546-555.

Faulkner, F., Treacy, P., \& Prendergast, M. (2016). Analysing the correlation between secondary mathematics curriculum change and trends in beginning undergraduates' performance of basic mathematical skills in Ireland. Irish Educational Studies, 35, 381-401.

King, D., \& Cattlin, J. (2015). The impact of assumed knowledge entry standards on undergraduate mathematics teaching in Australia. International Journal of Mathematical Education in Science and Technology, 46, 1032-1045.

Lee, S., Harrison, M.C., Pell, G. \& Robinson, C.L. (2008). Predicting performance of first year engineering students and the importance of assessment tools therein. Engineering Education, 3, 44-51.

Ní Fhloinn, E., Bhaird, C. M., \& Nolan, B. (2014). University students' perspectives on diagnostic testing in mathematics. International Journal of Mathematical Education in Science and Technology, 45, 58-74.

Rylands, L.J. \& Shearman, D. (2018). Mathematics learning support and engagement in first year engineering. International Journal of Mathematical Education in Science and Technology, 49, 1133-1147.

Treacy, P. \& Faulkner, F. (2015). Trends in basic mathematical competencies of beginning undergraduates in Ireland, 2003-2013. International Journal of Mathematical Education in Science and Technology, 46, 1182-1196.

Wilkes, J. \& Burton, L.J. (2015). Get Set for Success: Applications for engineering and applied science students. International Journal of Innovation in Science and Mathematics Education (formerly CAL-laborate International), 23, 94-105.

Wilson, R. \& Mack, J. (2014). Declines in high school mathematics and science participation: evidence of students' and future teachers' disengagement with maths. International Journal of Innovation in Science and Mathematics Education (formerly CAL-laborate International), 22, 35-48. 